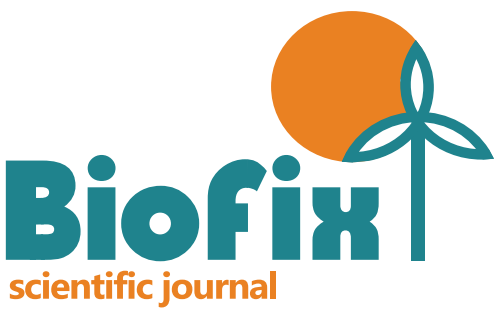

v. 2 n. 22017

Recebido em 12/06/2017

Aceito em 21/07/2017

Publicado em 10/08/2017

DOI: dx.doi.org/10.5380/biofix.v2i2.53230

\title{
MODELO DE FOMENTO FLORESTAL NAS INSTITUIÇÕES ESTADUAIS NOS ESTADOS DO SUL, SÃO PAULO E MINAS GERAIS
}

FORESTRY FOMENT MODEL IN STATE AGENCIES IN SOUTH STATES, SÃO PAULO, AND MINAS GERAIS

\author{
Rozane de Loyola Eisfeld ${ }^{1}$ \\ Luis Gustavo Socher ${ }^{2}$ \\ Corina Carril Ribeiro ${ }^{3}$
}

\author{
Universidade Federal do Paraná, Curitiba, Paraná, Brasil \\ rozaneloyolaeisfeld@hotmail.com ${ }^{1}$ \\ Companhia Paranaense de Energia, Curitiba, Paraná, Brasil \\ luis.socher@copel.com² \\ Companhia de Habitação do Paraná, Curitiba, Paraná, Brasil \\ carrilribeiro@yahoo.com.br ${ }^{3}$
}

\section{RESUMO}

O presente trabalho teve como objetivo avaliar estratégias de fomento florestal adotadas pelas instituições públicas nos estados do Sul, São Paulo e Minas Gerais, além de analisar as linhas de crédito disponíveis para o setor e as dificuldades para acessá-las. Para tal fim, realizou-se um levantamento bibliográfico dessas informações e entrevistas in loco com os técnicos de cada instituição. $\mathrm{Na}$ análise das linhas de crédito, conclui-se que o país avançou consideravelmente na quantidade e na diversidade de linhas, com recursos, taxas e tempo de carência adequados. A análise dos programas de fomento mostrou um modelo de fomento completo para o Paraná, contendo cinco treinamentos e assistência técnica, desde a elaboração de projeto para o financiamento até a venda da madeira para o mercado. Em Santa Catarina, o modelo de fomento é restrito em assistência técnica de plantio e na elaboração de projeto para financiamento. No Rio Grande do Sul, o modelo de fomento é bastante incipiente, o qual ocorre só por iniciativa das prefeituras. Em São Paulo existe pouca interferência dos órgãos estaduais, com modelos de fomento restrito entre produtores e empresas florestais. Minas Gerais foi o único estado que apresentou diversos programas de fomento, os quais divergem conforme as necessidades de cada produtor (fomento ambiental ou de produção), além de ser o único que possibilita distribuir insumos e ter programa específico para recuperação de áreas degradadas com espécies nativas. Com anos de tradição em fomento florestal, Minas Gerais é estado que apresentou a estratégia de fomento mais completa.

\begin{abstract}
The present study aimed to validate forestry foment strategies adopted by state agencies in the South States, São Paulo, and Minas Gerais, as well as to evaluated the credit lines available for the sector and the difficulties founded by producers to access them. For this purpose, we performed a bibliographic review of these information and personal interview with the staff of each institution. In the credit lines analysis, we concluded that the country has advanced greatly in quantity and diversity of lines, with features, rates, and adequate lacked time. The foment programs analysis revealed a complete foment model in the Paraná State, containing five trainings and technical assistance from project elaboration for financing to the wood sale. In Santa Catarina, the foment model is restrict in technical assistance for planting and in project's development to funding. In Rio Grande do Sul, the foment model is quite incipient, which occurs only at the initiative of municipalities. In São Paulo, there is small interference from state agencies, with foment models restricted between producers and forestry companies. Minas Gerais was the unique state that presents some varied types of foment programs, that are distinguished by the necessities of each producer (environmental foment or production foment), beyond to be the unique to distribute input and has a specific program to degraded recuperate areas with native species. With years of foment forestry tradition, Minas Gerais State had the most complete and efficient foment strategy.
\end{abstract}

KEYWORDS: Rural producer, Strategy, Rural extension, Credit lines.
PALAVRAS-CHAVE: Produtor rural, Estratégia, Extensão rural, Linhas de crédito. 


\section{INTRODUÇÃO}

A criação dos Programas de Fomento Florestal, seja pela iniciativa privada ou pública, tem como objetivo principal possibilitar a oferta de matéria-prima florestal por meio da participação de pequenos e médios produtores rurais em programas de reflorestamento, desconcentrando a área de formação de florestas e possibilitando a redução da pressão sobre as florestas naturais (SIQUEIRA et al., 2004). De acordo com IPEF (1992), fomento florestal seria uma série de ações protagonizadas por produtores rurais, empresas, poder público e outros, visando a produção de florestas econômicas de baixo custo.

$\mathrm{Na}$ visão dos órgãos públicos, os Programas de Fomento Florestal estão embasados nas seguintes premissas: 1) necessidade de implantar florestas artificiais para suprir as necessidades de consumo de madeira; 2) criar a possibilidade da oferta pelo produtor rural de matéria-prima de origem florestal; 3) promover o recobrimento arbóreo das áreas ociosas de pequenas e médias propriedades rurais; 4) gerar um aporte de renda adicional na economia familiar; e 5) diversificar a produção no meio rural. Para as empresas florestais, os programas de fomento são elaborados para, além de atender os aspectos citados anteriormente, criar alternativas de fornecimento de matéria-prima e permitir a desconcentração dos plantios.

Historicamente, os programas privados de fomento florestal se desenvolveram no Brasil junto com o próprio setor. Em 1903, a Companhia Paulista de Estradas de Ferro fomentou o eucalipto por meio de um programa de divulgação do gênero, entrega de prêmios pecuniários aos lavradores, doação de mudas e assistência técnica. Entre as décadas de 1920 a 1950, o conceito foi disseminado principalmente nos estados que concentravam as indústrias metalúrgicas, de mineração e de celulose. Nas décadas de 1960 e 1970, ocorreu a formação da base florestal nacional em larga escala com os incentivos fiscais, visando à área operacional (GARLIPP, 2006).

Nas décadas de 1980 e 1990, iniciaram-se os programas de fomento das principais indústrias e empresas florestais. Em 1980, o fomento foi do tipo extensão, por meio do fornecimento de mudas, assistência técnica e preferência de compra. Em 1990, o fomento passou a ser contratual, com a inclusão de adiantamentos financeiros ao produtor, orientação para adequação ambiental e manejo, garantia de compra de madeira, desconto no futuro do equivalente em madeira (GARLIPP, 2006).

Os fomentos públicos, desenvolvidos principalmente pelos órgãos de extensão, iniciaram no Brasil nas décadas de 1950 e 1960. O primeiro programa de fomento florestal público iniciou em 1958 no estado de Minas Gerais, com o Projeto de Reflorestamento para Produtores Rurais (FERRETI et al., 2001). Os demais estados iniciaram seu programa de fomento mais tardiamente, por volta da década de 1980 e 1990. Tal iniciativa voltada exclusivamente para o setor florestal foi impulsionada, principalmente, pela escassez de matéria-prima plantada e pela própria iniciativa privada que necessitava de apoio do poder público.

Segundo a Câmara Setorial de Silvicultura (2014), as linhas de financiamento que agem paralelamente às atividades do fomento florestal são fundamentais para o desenvolvimento da atividade florestal, principalmente por parte dos pequenos e médios produtores rurais. As linhas de crédito atualmente são usadas para pequenos projetos operacionalizados por bancos públicos federais, por meio das concessões do Ministério da Agricultura, Pecuária e Abastecimento (MAPA) e do Ministério do Desenvolvimento Agrário (MDA).

O presente artigo teve como objetivo avaliar estratégias de fomento florestal adotadas pelas instituições públicas nos estados do Sul, São Paulo e Minas Gerais, além de analisar as linhas de crédito disponíveis para o setor e as dificuldades para acessá-las.

\section{MATERIAL E MÉTODOS}

O desenvolvimento da metodologia empregada no presente estudo contemplou duas fases. Durante a primeira fase, definiu-se os estados a serem abordados, sendo eles: São Paulo, Minas Gerais, Paraná, Santa Catarina e Rio Grande do Sul; e realizou-se uma revisão bibliográfica sobre as linhas de créditos e os modelos de fomento florestal.

$\mathrm{Na}$ segunda etapa, identificou-se o órgão estadual responsável pelos projetos de fomento, os quais foram contatados por via contato telefônico por meio dos seus profissionais responsáveis. Nessa oportunidade, ocorreu o agendamento de visitas aos órgãos competentes, os quais ocorreram entre outubro de 2014 e abril de 2015. Os profissionais foram indagados, via questionário, quanto a oferta de linhas de crédito estaduais para o setor florestal, as dificuldades de acesso e os modelos de fomento florestais existentes, bem como suas estratégias de desenvolvimento.

A Tabela 1 apresenta a lista dos órgãos visitados, os quais são responsáveis pelos projetos de fomento florestal, o objetivo principal da instituição e seu endereço. 
Tabela 1. Órgãos estaduais de fomento florestal

\begin{tabular}{|c|c|c|c|c|}
\hline Estado & Sigla & Instituição & Objetivo & Endereço \\
\hline PR & EMATER & $\begin{array}{l}\text { Instituto Paranaense de } \\
\text { Assistência Técnica e } \\
\text { Extensão Rural do Paraná }\end{array}$ & $\begin{array}{l}\text { Promover o desenvolvimento rural sustentável (fomento, } \\
\text { assistência técnica e extensão rural) }\end{array}$ & $\begin{array}{l}\text { Rua da Bandeira 500, } \\
\text { Cabral, Curitiba/PR } \\
\text { Tel.: (41)3250-2100 }\end{array}$ \\
\hline SC & EPAGRI & $\begin{array}{l}\text { Empresa de Pesquisa } \\
\text { Agropecuária e Extensão } \\
\text { Rural de Santa Catarina }\end{array}$ & $\begin{array}{l}\text { Preservar o meio-ambiente, melhorar a qualidade de vida e } \\
\text { desenvolver uma agricultura competitiva, promovendo o } \\
\text { desenvolvimento sustentável dos meios rural e pesqueiro, em } \\
\text { benefício de toda a sociedade catarinense. Desenvolver os } \\
\text { recursos florestais no estado. }\end{array}$ & $\begin{array}{l}\text { Rod. Admar Gonzaga } \\
\text { 1.347, Itacorubi, } \\
\text { Florianópolis/SC } \\
\text { Tel.:(48)3239-5500 }\end{array}$ \\
\hline RS & EMATER & $\begin{array}{l}\text { Empresa de Assistência } \\
\text { Técnica e Extensão Rural do } \\
\text { Rio Grande do Sul }\end{array}$ & $\begin{array}{l}\text { Promover o desenvolvimento rural sustentável por meio de } \\
\text { ações de assistência técnica e extensão rural, mediante processos } \\
\text { educativos e participativos, visando o fortalecimento da } \\
\text { agricultura familiar e criando condições para o pleno exercício da } \\
\text { cidadania e a melhoria da qualidade de vida da população } \\
\text { gaúcha. }\end{array}$ & $\begin{array}{l}\text { Rua Botafogo 1.051, } \\
\text { Menino de Deus, Porto } \\
\text { Alegre/RS } \\
\text { Tel.:(51)2125-3020 }\end{array}$ \\
\hline SP & CATI & $\begin{array}{l}\text { Coordenadoria de } \\
\text { Assistência Técnica Integral } \\
\text { de São Paulo }\end{array}$ & $\begin{array}{c}\text { Promover o desenvolvimento rural sustentável, por meio de } \\
\text { programas e ações participativas com o envolvimento da } \\
\text { comunidade, de entidades parceiras e de todos os segmentos dos } \\
\text { negócios agrícolas. }\end{array}$ & $\begin{array}{l}\text { Av. Brasil 2.340, Bairro } \\
\text { Vila Itapura, } \\
\text { Campinas/SP } \\
\text { Tel.:(19)3743-3700 }\end{array}$ \\
\hline MG & IEF & $\begin{array}{l}\text { Instituto Estadual de } \\
\text { Florestas }\end{array}$ & $\begin{array}{l}\text { Propor e executar as políticas florestais. Autarquia vinculada à } \\
\text { SEMAD responsável pela preservação e a conservação da } \\
\text { vegetação, pelo desenvolvimento sustentável dos recursos } \\
\text { naturais renováveis; pela pesquisa em biomassas e } \\
\text { biodiversidade; pelo inventário florestal e o mapeamento da } \\
\text { cobertura vegetal do estado. }\end{array}$ & $\begin{array}{l}\text { Rod. Prefeito Américo } \\
\text { Gianetti, Serra Verde, } \\
\text { Belo Horizonte/MG } \\
\text { Tel.: (31)3915-1379 }\end{array}$ \\
\hline MG & EMATER & $\begin{array}{l}\text { Empresa de Assistência } \\
\text { Técnica e Extensão de Minas } \\
\text { Gerais }\end{array}$ & $\begin{array}{l}\text { Promover o desenvolvimento sustentável, por meio da } \\
\text { assistência técnica e extensão rural, assegurando a melhoria da } \\
\text { qualidade de vida da sociedade mineira. }\end{array}$ & $\begin{array}{c}\text { Av. Raja Gabáglia 1.626, } \\
\text { B. Gutierrez, Belo } \\
\text { Horizonte/MG } \\
\text { Tel.:(31)3349-8234 }\end{array}$ \\
\hline
\end{tabular}

Com base nas entrevistas e na metodologia empregada para a coleta de informações, realizou-se:

1. Análise das linhas de crédito estaduais disponíveis e as dificuldades de acesso;

2. Diagnóstico dos modelos de fomento adotados em cada estado, assim como os resultados positivos e negativos obtidos; e

3. Análise comparativa entre os estados do modelo de fomento florestal que apresentou os melhores resultados.

\section{RESULTADOS E DISCUSSÃO}

\section{Linhas de financiamento para o setor florestal}

Segundo Mendes (2014), com o fim dos incentivos fiscais entre as décadas de 1960 a 1980, as plantações florestais passaram a ser custeadas com recursos próprios ou com financiamento de agentes financeiros, principalmente pelo setor de papel e celulose. Foi então que a partir desse momento houve uma forte atuação do Banco Nacional de Desenvolvimento (BNDES), disponibilizando recursos destinados aos projetos florestais.

O BNDES atualmente é uma das mais importantes fontes de financiamento ao reflorestamento, apoiando as unidades industriais com florestas próprias ou as empresas florestais que possuem contratos de fornecimento ao longo prazo. Entre 1991 e 2001, o banco nacional desembolsou cerca de US\$ 435 milhões para o reflorestamento de cerca de 528 mil hectares, incluindo reforma, implantação de viveiros e pesquisas florestais (MENDES, 2014).

Um marco importante para as linhas de financiamento foi a criação do Programa Nacional de Florestas (PNF) em abril de 2000, por meio do decreto $n$ ㅇ 3.420, cujo objetivo foi articular as políticas públicas setoriais, buscando promover o desenvolvimento sustentável, e conciliar o uso com a conservação das florestas brasileiras. O programa é constituído de projetos concebidos e executados de forma participativa e integrada pelos governos federal, estaduais, distrital e municipais e a sociedade civil organizada. Essa articulação é feita pelo Ministério do Meio Ambiente (MMA). Em 2007, por meio do decreto no 6.101, foi 
definida uma nova estrutura regimental no MMA, em que o PNF passou a ser coordenado pelo Departamento de Florestas (DFLOR) (MMA, 2014).

Em 2002, foi lançado o Programa de Plantio Comercial e Recuperação de Florestas (PROPFLORA), coordenado pelo Ministério da Agricultura, Pecuária e Abastecimento (MAPA) em conjunto com a promoção do PNF, que visou o apoio aos pequenos e médios produtores rurais em implantar e manter as suas florestas comerciais com recursos técnicos e mão-de-obra apropriados (MENDES, 2014). Em 2012, o Propflora e o Programa de Estímulo à Produção Agropecuária Sustentável (PRODUSA) foram incorporados ao Programa de Agricultura de Baixo Carbono (ABC).

Atualmente, além das linhas de crédito já mencionadas, o setor conta com outras, as quais possuem finalidades distintas. A relação das principais linhas de crédito para o setor e demais aspectos relevantes (crédito, taxa, carência e finalidade) estão resumidos na Tabela 2.

\section{Dificuldades de acesso às linhas de crédito}

\section{Estado do Paraná}

No estado do Paraná não existem linhas de crédito estaduais que abranjam o setor florestal. Em alguns casos, para pequenos produtores, o estado pode participar como avalista, porém as linhas de crédito disponíveis são todas federais.

A percepção é que há linhas de crédito e dinheiro suficientes para financiamento, uma vez que o PRONAF, no ano de 2012, disponibilizou ao estado R\$ 900 milhões. Entretanto, segundo os técnicos da Instituto Paranaense de Assistência Técnica e Extensão Rural (EMATER), poucos são os produtores que conseguem recursos para a atividade florestal. Acredita-se que o principal entrave está na ponta final da cadeia: entre o gerente do banco e o produtor.

Nos bancos existem cinco grandes barreiras que dificultam a liberação do financiamento: 1) falta de divulgação das linhas de crédito, prejudicando que haja uma orientação adequada dos funcionários aos produtores; 2) falta de experiência dos gerentes do banco com plantios florestais; 3 ) empréstimos de longo prazo são considerados de alto risco para o banco, dificultando a liberação do crédito; 4) falta de estrutura técnica nas agências para avaliar os projetos florestais; e 5) calendário de liberação de financiamento direcionado ao calendário agrícola, o qual se difere do setor florestal.

\section{Estado de Santa Catarina}

Durante o período de 1990 a 1999, o governo estadual conduziu o Projeto Microbacias com objetivo de proteção e recuperação dos solos. Foram destinados recursos financeiros para plantios de até 5 ha por produtor. Tal projeto obteve bons resultados, mas encontra-se finalizado.

O governo de Santa Catarina também possuía o Projeto Florestal de Geração de Trabalho e Renda, onde pagava-se o equivalente a 0,5 salário mínimo por mês por hectare plantado durante quatro anos, com limite de 2 ha plantados por propriedade. Esse valor mensal era convertido em empréstimo, cujo pagamento era estabelecido no momento do contrato e realizado após a colheita em valor monetário equivalente a uma parte da madeira a ser comercializada. Por problemas políticos e técnicos, o programa foi suspenso. Hoje existe um grande impasse em como finalizar o programa, pois durante o andamento do projeto, os produtores pararam de receber os recursos financeiros, assim como o governo não recebeu o ressarcimento dos empréstimos.

Atualmente não há linhas de crédito estaduais no estado de Santa Catarina. Existe, apenas, assistência técnica para acessar as linhas federais, principalmente o Pronaf-ECO. Além disso, assim como no estado do Paraná, as percepções também se convergem na existência de linhas de crédito e recursos suficientes para plantios florestais. A Empresa de Pesquisa Agropecuária e Extensão Rural de Santa Catarina (EPAGRI) elabora junto aos produtores o projeto técnico necessário para aprovação do crédito nos bancos. Os únicos gargalos apontados pelos técnicos são as exigências legais de acesso, como situação fundiária regularizada, georreferenciamento, entre outros.

\section{Estado do Rio Grande do Sul}

No Rio Grande do Sul não há linhas de crédito estaduais, existe apenas assistência técnica para acessar as linhas federais, principalmente o Pronaf-Florestal e o Pronaf-Eco. Segundo os técnicos da EMATER, as linhas de crédito são suficientes, a taxa é considerada apropriada, o volume de recursos por proprietário é suficiente e o tempo de carência é adequado. Entretanto, as linhas de crédito existentes exigem o Licenciamento Ambiental aprovado. Segundo a EMATER, tal licenciamento é oneroso e moroso, o que inviabiliza os projetos. Ademais, nos últimos anos, o estado do Rio Grande do Sul tem utilizado um volume de recursos muito inferior ao destinado ao estado. 
Tabela 2. Linhas de crédito federais para a área florestal, crédito, taxa, carência e finalidade

\begin{tabular}{|c|c|c|c|c|c|}
\hline Programa & Crédito (R\$) & Prazo Máximo & Carência & Taxa de Juros & Finalidade \\
\hline $\begin{array}{c}\text { Programa ABC } \\
\text { (Propflora e } \\
\text { Produsa) }\end{array}$ & 5 milhões & $\begin{array}{l}\text { Até } 12 \text { anos } \\
\text { (projetos } \\
\text { florestais) }\end{array}$ & Até 8 anos & $7,5 \%$ ao ano & $\begin{array}{l}\text { Implantação, manutenção e manejo de florestas comerciais; } \\
\text { recuperação de áreas de pastagens degradadas; implantação } \\
\text { de sistemas de integração lavoura-pecuária-floresta; } \\
\text { adequação ou regularização das propriedades frente à } \\
\text { legislação ambiental; entre outros. }\end{array}$ \\
\hline $\begin{array}{l}\text { BNDES } \\
\text { Finem }\end{array}$ & >20 milhões & 20 anos & & $\begin{array}{c}\text { TJLP + Taxa } \\
\text { BNDES (2,1\% a } \\
6,56 \% \text { ao ano) }\end{array}$ & $\begin{array}{c}\text { Apoio ao reflorestamento, conservação e recuperação de } \\
\text { áreas degradadas e ao manejo florestal sustentável em áreas } \\
\text { nativas; plantio de espécies florestais com fins energéticos; } \\
\text { reflorestamento de áreas degradadas ou convertidas ao } \\
\text { manejo florestal; e plantio de espécies nativas para } \\
\text { recuperação de áreas degradadas. }\end{array}$ \\
\hline $\begin{array}{c}\text { PRONAF } \\
\text { FLORESTAL/MDA } \\
\text { (Agricultores } \\
\text { familiares) }\end{array}$ & Até $38,5 \mathrm{mil}$ & Até 20 anos & 12 anos & $2,5 \%$ ao ano & $\begin{array}{l}\text { Financiamento de sistemas agroflorestais; exploração } \\
\text { extrativista ecologicamente sustentável; plano de manejo } \\
\text { florestal; recomposição e manutenção de áreas de } \\
\text { preservação permanente e reserva legal; reflorestamento; } \\
\text { entre outros. }\end{array}$ \\
\hline $\begin{array}{c}\text { PRONAF } \\
\text { ECO/MDA } \\
\text { (Agricultores } \\
\text { familiares) }\end{array}$ & Até 165 mil & Até 12 anos & 8 anos & $5,5 \%$ ao ano & $\begin{array}{l}\text { Financiamento para implantação de tecnologias de energia } \\
\text { renovável, obras de irrigação e de armazenamento hídrico; } \\
\text { florestamento e reflorestamento; proteção e recuperação do } \\
\text { solo; entre outras atividades relacionadas ao cultivo de } \\
\text { árvores }\end{array}$ \\
\hline
\end{tabular}

Fontes: Banco do Brasil (2017) e BNDES (2017).

\section{Estado de São Paulo}

No estado de São Paulo também não há linhas de crédito estaduais que abranjam o setor florestal. Segundo os técnicos da Coordenadoria de Assistência Técnica Integral de São Paulo (CATI), existem linhas de créditos federais com recursos suficientes. O gargalo está na falta de divulgação das linhas por parte dos funcionários dos bancos aos produtores florestais.

\section{Estado de Minas Gerais}

No estado de Minas Gerais também não há linhas de créditos estaduais. Existe apenas assistência técnica para acessar as linhas federais, principalmente o Pronaf. Segundo os técnicos da EMATER, existem linhas de crédito e recursos suficientes para plantios florestais. A EMATER também elabora junto aos produtores o projeto técnico necessário para aprovação do crédito nos bancos. Os gargalos foram identificados entre o gerente e o produtor, tais como atividade florestal considerada de alto risco pelo gerente do banco, com a necessidade de elevados volumes de recursos. Sendo assim, grande parte do recurso é destinado aos grandes produtores florestais, visando minimização dos riscos.

\section{Modelos de fomento e assistência técnica}

\section{Estado do Paraná}

O projeto de fomento florestal no estado do Paraná teve início em 1992, sendo alterado diversas vezes, cujo modelo atual perdura desde o ano de 2000. o ciclo de fomento no Paraná inicia-se a partir de uma empresa florestal interessada em ampliar sua área. Nesse momento, ocorre o primeiro contato entre a empresa interessada e a instituição fomentadora, a qual descreve o projeto planejado, como região de interesse e área necessária para plantio. A EMATER organiza a primeira reunião com os produtores da região interessados no programa de fomento com a presença de, aproximadamente, 200 a 300 produtores rurais.

Após um mês ocorre a segunda reunião, em que retornam de 20 a $30 \%$ dos produtores participantes da primeira reunião, entretanto, têm-se a premissa que a reunião contenha, no mínimo, 25 produtores. Nela, os produtores repassam para a empresa a área disponível para plantio e calcula-se então o número de mudas necessária para cada produtor. O produtor, então, efetua o pagamento, estipulado em R\$ 0,09 por muda. Desse montante, $R \$ 0,02$ é repassado para a EMATER.

Os produtores participam da terceira reunião realizada 
pela EMATER com o objetivo repassar conhecimentos operacionais em silvicultura aos produtores rurais, com foco em: plantio, primeiros tratos silviculturais, preparo de solo, primeiros cuidados com as mudas, controle de formigas. Após o treinamento, o produtor recebe as mudas, o formicida e, em alguns casos, o adubo da empresa fomentadora Com os insumos disponíveis, os produtores efetuam o plantio e o replantio.

Noventa dias após o plantio, ocorre a quarta reunião com objetivo de ensinar as técnicas de manejo, como: condução da floresta, manutenção, desbaste e poda. Alguns meses antes da colheita ocorre a sexta reunião, visando orientar os produtores sobre as técnicas de colheita e o mercado. Por fim, ocorre a colheita nas áreas fomentadas.

A empresa fomentadora tem preferência de compra ao preço de mercado. Estima-se que 93\% da madeira fomentada retornem a empresa. Nesse momento, ocorre o final do ciclo de fomento entre a EMATER, a empresa fomentadora e o produtor rural. Quando não há uma empresa que inicie esse ciclo, o produtor rural tem como opção se dirigir até a EMATER, onde receberá capacitação em silvicultura e assistência na elaboração do projeto para obtenção de financiamento para o plantio.

\section{Estado de Santa Catarina}

Para iniciar o ciclo de fomento, primeiramente os técnicos da EPAGRI recebem treinamentos específicos em silvicultura, o qual é dividido em três etapas: 1) preparo de solo, plantio e manutenção; 2) tratos silviculturais (poda, desbaste e manutenção); e 3) colheita.

Fica sob responsabilidade das prefeituras locais e das empresas da região identificar e incentivar os proprietários de terras. Os técnicos da EPAGRI fornecem assistência técnica aos produtores, nos seguintes procedimentos: técnicas de plantio, acompanhamento dos plantios e elaboração de projeto técnico de acesso ao crédito. Caso haja alguma empresa fomentadora na região, há repasse de mudas. Caso contrário, o produtor adquire mudas nos viveiros da região.

Atualmente, a EPAGRI conta com 40 técnicos capacitados em silvicultura, principalmente de pinus e eucalipto. Há projeto de duplicação do número de técnicos capacitados até 2018.

\section{Estado do Rio Grande do Sul}

No estado do Rio Grande do Sul, o processo inicia nas prefeituras, em que os municípios identificam os produtores interessados no plantio de espécies florestais.

A EMATER se responsabiliza em realizar a assistência técnica e acompanhar os plantios. As prefeituras repassam mudas e insumos (calcário e adubo), entretanto os critérios de doação dos insumos ficam a critério de cada prefeitura. Em 2013, foram assistidos 221 municípios em silvicultura, 7 mil agricultores familiares e 24 mil ha cultivados.

Não existe treinamento específico em silvicultura fornecido aos técnicos da EMATER. Segundo o funcionário entrevistado, pela formação dos técnicos, eles estão capacitados em silvicultura.

A Secretaria do Ambiente e Desenvolvimento Sustentável (SEMA) também tem projetos de incentivo ao plantio de araucária e outras espécies nobres, por meio da doação de mudas.

\section{Estado de São Paulo}

O fomento florestal no estado de São Paulo tem sido orientado para produção de matéria-prima para indústria de papel e para energia, graças principalmente às empresas privadas que atuam no setor e às associações de reposição florestal, que vêm incentivando o plantio quase que exclusivamente de florestas homogêneas de espécies exóticas. As espécies nativas representam uma parcela muito pequena no fomento florestal em São Paulo (FERRETTI et al., 2001).

Conforme descrito pelos técnicos da CATI, o atual fomento florestal em São Paulo está restrito às empresas de base florestal com produtores rurais, sem intervenção do Estado. Nas regionais de Bragança Paulista, Guaratinguetá e Pindamonhangaba, os técnicos da CATI estão sendo treinados em silvicultura pelas empresas florestais. $O$ intuito é de que os técnicos apoiem o Projeto Poupança Florestal, conduzido pelas empresas. Tal projeto será implantado em 57 municípios. Além de desenvolver educação ambiental, o Poupança Florestal visa ampliar os estoques florestais da região e introduzir alternativas de uso para áreas inadequadamente exploradas e propriedades economicamente fragilizadas (SAA, 2013).

No Programa Poupança Florestal, as seguintes atividades serão de responsabilidade dos técnicos da CATI: 1) planejamento da propriedade; 2) indicação dos locais adequados para plantio como fonte adicional de renda; e 3) assistência na recuperação de áreas.

O estado de São Paulo conduziu até 2010, o programa estadual de microbacias hidrográficas. Esse programa contemplou 464 municípios e visou a recuperação de áreas degradadas, recomposição e manutenção de matas ciliares. A CATI, por sua vez, foi responsável pelo 
fornecimento das mudas e assistência técnica ao plantio. Entretanto, tal programa encontra-se atualmente finalizado.

\section{Estado de Minas Gerais}

Diferentemente dos demais estados, o fomento florestal em Minas Gerais não é conduzido pela EMATER, e sim pelo Instituto Estadual de Florestas (IEF). Ele é dividido em dois grupos: 1) fomento de produção; e 2) fomento ambiental. Dentro do fomento de produção, o IEF incentiva três modalidades de programas: fomento para reposição florestal, social e plantio de florestas de proteção com espécies nativas.

O fomento para reposição florestal é feito com recursos captados junto aos consumidores de produtos florestais e aplicados na produção de mudas de boa qualidade em viveiros próprios, de acordo com o estabelecido pela Lei Estadual 14.309, de 19 de junho de 2002. O plantio das mudas é feito pelos produtores rurais parceiros, segundo critérios técnicos e ambientais.

A reposição florestal é o conjunto de ações desenvolvidas para estabelecer a continuidade do abastecimento de matéria-prima florestal aos diversos segmentos consumidores, por meio da obrigatoriedade da recomposição do volume explorado, mediante o plantio de espécies florestais adequadas ao consumo. A reposição florestal é feita, preferencialmente, no território do município produtor, sendo regulamentada pela Resolução 002/1994 e pela Portaria IEF no 31/1996 (IEF, 2013a).

Na modalidade de fomento de produção, o IEF doa as mudas, o adubo, o formicida e fornece assistência técnica. Após o plantio, por meio de técnicas de georreferenciamento, os técnicos do IEF validam a área plantada.

O fomento social é realizado com produtores cadastrados junto ao IEF que possuam plantios com menos de três hectares para suprimento de madeira nas propriedades. A entrega de mudas é feita pelo IEF que também realiza orientações sobre plantio. As mudas são desenvolvidas nos viveiros do IEF em parceria com as prefeituras e as comunidades (IEF, 2013a).

O fomento com empresa está vinculado a uma empresa florestal que deseja aumentar sua área por meio do fomento florestal. O IEF é responsável em dar suporte à empresa, cadastrando produtores e escolhendo as áreas de plantio. O acompanhamento do plantio e pós-plantio é realizado pela empresa fomentadora.

O segundo grupo de fomento executado pelo IEF é denominado fomento ambiental. Ele é desenvolvido com espécies nativas e voltado para a recuperação e o enriquecimento das matas ciliares, de áreas de recarga hídrica e de áreas degradadas. O objetivo é a conservação do solo, da água e da fauna (IEF, 2013b).

Ele é dividido em quatro subgrupos: 1) mata ciliar; 2) mata de topo; 3) área degradada; e 4) proteção de nascente. Em todas elas, o IEF fornece orientação, planejamento, insumos de viveiro e de plantio, cercamento e acompanhamento técnico. A prefeitura, por sua vez, disponibiliza um funcionário responsável pelo cadastro de produtores, da área para instalação de um viveiro, da divulgação do trabalho, da orientação e do acompanhamento do plantio.

Historicamente, o estado de Minas Gerais é pioneiro no Programa de Fomento Florestal no Brasil iniciado em 1958. Atualmente, o IEF assiste, em média, mais de 6.000 produtores por ano, sendo 2.500 no fomento ambiental e 3.500 no de produção. Em média, são plantados 30.000 ha por ano, sendo 10.000 no fomento ambiental e 20.000 no de produção.

O estado de Minas Gerais, sob responsabilidade do IEF, também conta com o Programa Bolsa Verde. Iniciado em 2010, o programa tem por objetivo apoiar a conservação da cobertura vegetal nativa em Minas Gerais, mediante pagamento por serviços ambientais aos proprietários e aos posseiros que preservam ou que se comprometem a recuperar a vegetação de origem nativa em suas propriedades ou posses. A prioridade é para agricultores familiares e pequenos produtores rurais com menos de quatro módulos fiscais.

O incentivo financeiro é proporcional à dimensão da área preservada. Assim, recebe mais quem preservar mais, até o limite de hectares correspondente a quatro módulos fiscais em seu respectivo município, com valor atual de $\mathrm{R} \$$ 200 por hectare. O proprietário recebe esse valor por cinco anos, com vistoria anual realizada pelos técnicos do IEF. Em 2013, foram recebidas 2.500 inscrições e avaliadas 1.023 áreas, sendo destinado 7,0 milhões de reais.

\section{Comparação entre os estados}

Os principais tópicos das estratégias de fomento adotadas em cada um dos cinco estados analisados foram tabulados e apresentados de forma comparativa (Tabela 3). De modo geral, percebe-se estratégias heterogêneas entre as instituições estaduais, em que o modelo de fomento no Paraná é bastante complexo, contemplando cinco treinamentos e assistência técnica desde a elaboração do projeto para o financiamento, até a venda da madeira para o mercado. 
Tabela 3. Comparação entre as estratégias de fomento florestal das instituições estaduais

\begin{tabular}{cccccc}
\hline Item & PR & SC & RS & SP & MG \\
\hline $\begin{array}{c}\text { Existe uma instituição voltada ao } \\
\text { fomento específico no setor florestal? }\end{array}$ & Não & Não & Não & Não & Sim (IEF) \\
\hline Quem inicia o ciclo de fomento? & $\begin{array}{c}\text { Empresa } \\
\text { fomentadora }\end{array}$ & $\begin{array}{c}\text { Empresa, prefeitura } \\
\text { e EPAGRI }\end{array}$ & Prefeitura & $\begin{array}{c}\text { Empresa } \\
\text { fomentadora }\end{array}$ \\
$\begin{array}{c}\text { Os técnicos possuem capacitação em } \\
\text { silvicultura? }\end{array}$ & Sim & Sim & Não & $\begin{array}{c}\text { Sim (algumas } \\
\text { regionais) }\end{array}$ & Sim \\
$\begin{array}{c}\text { A instituição participa dos projetos de } \\
\text { fomento liderados pelas empresas? }\end{array}$ & Sim & Sim & Não & $\begin{array}{c}\text { Não (irá começar o } \\
\text { Poupança Florestal) }\end{array}$ & Sim \\
$\begin{array}{c}\text { Instituição fornece treinamentos em } \\
\text { silvicultura para produtores? }\end{array}$ & Sim & Sim & Não & Sim \\
$\begin{array}{c}\text { Há repasse de algum insumo de } \\
\text { plantio? }\end{array}$ & Não & Não & Não & Não & Sim \\
$\begin{array}{c}\text { A instituição fornece auxilio na } \\
\text { elaboração de projetos para obtenção } \\
\text { de financiamento? }\end{array}$ & Sim & Sim & Sim & Sim \\
$\begin{array}{c}\text { Existem projetos de fomento com } \\
\text { espécies nativas? }\end{array}$ & Não & Não & Sim & Sim \\
$\begin{array}{c}\text { Existe linha de crédito estadual para } \\
\text { plantios florestais? }\end{array}$ & Não & Não & Não & Sim \\
\hline
\end{tabular}

Entretanto, para que esse ciclo de fomento seja iniciado, é necessária uma empresa fomentadora. Portanto, o estado não é indutor de aumento de área com base no fomento. Assim, os resultados de ampliação de área base fomento estarão restritos às espécies e à região de interesse das empresas.

Em Santa Catarina, o modelo de fomento restringe-se a assistência técnica de plantio e elaboração do projeto para financiamento. Um ponto positivo apresentado nesse estado foi a preocupação em capacitar os técnicos da EPAGRI em conhecimentos específicos de silvicultura. Ao passo que no Rio Grande do Sul, o modelo de fomento é bastante incipiente, o qual ocorre por iniciativa das prefeituras. A EMATER apenas fornece assistência técnica de plantio e auxilia na elaboração de projeto para financiamento.

O setor florestal em São Paulo está baseado, principalmente, em grandes empresas florestais de celulose. Tais empresas iniciaram seus projetos de fomento há muitos anos, sem intervenção do estado. Tal realidade perdura até hoje, com modelos de fomento restrito entre produtores e empresas florestais.

Com um setor florestal antigo e tradicional, Minas Gerais possui a maior área de florestas plantadas no Brasil, com 1.640 mil hectares ( $25 \%$ do total nacional). Além das condições ambientais adequadas para plantio, ganhos de melhoramento genético e resultados de sucesso das empresas, o crescimento dos plantios no estado também são advindos da necessidade de reposição florestal pela Portaria IEF 08/1996 e da Lei Estadual 14.309/2002, a qual determina que a madeira de floresta nativa deverá compor só $5 \%$ da demanda até 2018.

Criado em 1962, o IEF auxiliou na ampliação e no desenvolvimento do setor florestas de Minas Gerais por meio de projetos de fomento florestal ao longo de mais de 59 anos. Além disso, destaca-se o estímulo para ampliação das áreas de reflorestamento, visando o auto-suprimento e a redução da pressão sobre as matas nativas.

A criação de um órgão específico para o setor florestal mostrou em Minas Gerais uma realidade de estratégia de fomento florestal muito diferente dos demais estados. Foi unicamente em Minas Gerais onde ocorre: 1) fornecimento de insumos para o plantio e recuperação de áreas, como mudas, adubo, formicida, cercamento, entre outros; 2) diversos modelos de fomento, adequados em função do objetivo final do produtor, seja para produção ou recuperação de área; 3) estado como o principal agente indutor do fomento, no qual empresas e prefeituras são apenas parceiros no projeto; e 4) projetos consistentes de fomento para recuperação de áreas com espécies nativas, além de programas de pagamento por serviços ambientais.

Historicamente, os órgãos de extensão estão focados nas áreas agrícola e pecuária, sendo ainda inicial o conhecimento e a assistência na área florestal. Em Minas Gerais, com a presença do IEF focado nas necessidades da área florestal, contendo funcionários também formados na área, fez com que o modelo de fomento e a assistência técnica atualmente praticada sejam bastante difundidos dentre os produtores, servindo como referência para os demais estados do país. 


\section{CONCLUSÕES}

Apesar do interesse do governo federal em duplicar a área de plantios florestais dos atuais 7,6 milhões de hectares para mais de 9 milhões de hectares, conforme objetivo 0750 e meta 046T do Plano Plurianual de 2016 do Ministério do Planejamento, Desenvolvimento e Gestão (MPDG), o Brasil ainda não possui um programa nacional de fomento florestal. Assim, coube aos órgãos estaduais de extensão desenvolver estratégias específicas para aumentar a área de plantio em cada estado.

Este trabalho, concentrado na região Sul e parte da Sudeste, apresenta modelos e estratégias de fomento bastante divergentes. Tem-se nos estados do Sul e São Paulo modelos impulsionados pelas empresas florestais, baseados principalmente em assistência técnica de plantio e elaboração de projeto para financiamento. Apenas em Minas Gerais, o órgão estadual de extensão apresenta-se como o agente indutor, tanto de aumento de área para o plantio, quanto de recuperação de áreas com espécies nativas.

Analisando exclusivamente a disponibilidade de crédito, conclui-se que o país avançou significativamente na quantidade e na diversidade de linhas, tendo recursos considerados suficientes e taxas e tempo de carência adequados. Entretanto, aponta-se que ainda existem dificuldades no final da cadeia entre o gerente dos bancos e o produtor, uma vez que a atividade florestal é considerada de alto risco pelos bancos, pois necessita de elevados volumes de recursos, além de tempo longo para colheita e, portanto, pagamento do empréstimo. Sendo assim, para que haja uma minimização dos riscos por parte dos bancos, os recursos são direcionados aos grandes produtores florestais.

Atualmente, é inegável os resultados econômicos positivos que o setor florestal proporciona ao Brasil, ainda mais em regiões inóspitas e com baixo Índice de Desenvolvimento Humano (IDH), onde a agricultura tornase inviável. Aliado a isso, tem-se no país condições edafoclimáticas favoráveis; elevada produtividade, obtida por meio de trabalhos de melhoramento genéticos e manejo florestal; disponibilidade de terra e mão de obra.

Apesar disso e do interesse do governo em aumentar a área de plantio, não há programas de fomento florestal na esfera federal, e muito menos subsídio para recuperação de áreas, seja por meio da doação de insumos ou de programas de assistência técnica. No momento em que esse quadro seja revertido, indica-se que o ponto de partida seja adotar estratégias semelhantes às desenvolvidas por técnicos no estado de Minas Gerais.

\section{REFERÊNCIAS}

BNDES - Banco Nacional do Desenvolvimento. BNDES Finem. 2017. Disponível em: <http://www.bndes.gov.br/wps/portal/site Lhome/financiamento/bndes-finem $>$. Acesso em: 17/07/2017.

BANCO DO BRASIL. Pronaf-Eco. 2017. Disponível em: $<$ http://www.bb.com.br/pbb/pagina-inicial/agronegocios/agron egocio---produtos-e-servicos/credito/investir-em-sua-atividade/ pronaf-eco\#/>. Acesso em: 19/07/2017.

CÂMARA SETORIAL DE SILVICULTURA. Agenda Estratégica do Setor de Florestas Plantadas. 2009. 36 p. Disponível em: <http://www.veracel.com.br/wp-content/uploads/2015/02/age nda silvicultura web.pdf> Acesso em: 27/08/2014.

FERRETTI, A. R.; KAGEYAMA, P. Y.; QUEDA, O. O programa de fomento florestal do viveiro da CESPE de Porto Primavera e a situação do fomento florestal com espécies nativas no Estado de São Paulo. Circular Técnica IPEF, n. 193, p. 1-8, 2001.

IEF - Instituto Estadual de Florestas. Fomento florestal. 2013a. Disponível em: <http://www.ief.mg.gov.br/florestas/fomentoflorestal >. Acesso em: 20/03/2013.

IEF - Instituto Estadual de Florestas. Bolsa verde. 2013b. Disponível em: <http://www.ief.mg.gov.br/bolsa-verde>. Acesso em: $20 / 03 / 2013$

IPEF - Instituto de Pesquisas Florestais. Silvicultura intensiva e o desenvolvimento sustentável. Série Técnica IPEF, v. 8, n. 24, p. 189, 1992.

GARLIPP, R. C. D. Mecanismo estratégico e de novas oportunidades. Revista Opiniões sobre o Fomento Florestal Brasileiro, p. 19, 2006.

MENDES, J. B. Estratégias e mecanismos financeiros para florestas plantadas. 2005. 66 p. Disponível em: $<$ http://www.mma.gov.br/estruturas/pnf/ arquivos/financia pl antadas.pdf>. Acesso em 27/07/2014.

MMA - Ministério do Meio Ambiente. Programa Nacional de Florestas. Disponível em: <http://www.mma.gov.br/florestas/ programa-nacional-de-florestas >. Acesso em: 27/07/2014.

MPDG - Ministério do Planejamento, Desenvolvimento e Gestão. Plano Plurianual 2016-2019 - Desenvolvimento, Produtividade e Inclusão Social. Anexo I. Brasília, 2015. 303 p.

SAA - Secretaria de Agricultura e Abastecimento. Novos projetos e posse de conselheiros marcam 40 anos da CATI. 2012 Disponível em: <http://www.saopaulo.sp.gov.br/spnoticias/ ultimas-noticias/novos-projetos-e-posse-de-conselheiros-marca m-40-anos-da-cati>. Acesso em: 19/03/2013.

SIQUEIRA, J. D. P.; LISBOA, R. S.; FERREIRA, A. M.; SOUZA, M. F. R.; ARAUJO, E.; LISBÃO JÚNIOR, L.; SIQUEIRA, M. M. Estudo ambiental para os programas de fomento florestal da Aracruz Celulose S.A. e extensão florestal do Governo do Estado do Espírito Santo. Revista Floresta, v. 34, n. 2, p. 3-67, 2004. 